\title{
Vital Signs: Status of Human Immunodeficiency Virus Testing, Viral Suppression, and HIV Preexposure Prophylaxis - United States, 2013-2018
}

Norma S. Harris, $\mathrm{PhD}^{1}$; Anna Satcher Johnson, MPH${ }^{1}$; Ya-Lin A. Huang, PhD ${ }^{1}$; Dayle Kern, MA ${ }^{1}$; Paul Fulton ${ }^{2}$; Dawn K. Smith, MD ${ }^{1}$; Linda A. Valleroy, $\mathrm{PhD}^{1}$; H. Irene Hall, $\mathrm{PhD}^{1}$

On December 3, 2019, this report was posted as an MMWR Early Release on the MMWR website (https://www.cdc.gov/mmwr).

\section{Abstract}

Background: Approximately 38,000 new human immunodeficiency virus (HIV) infections occur in the United States each year; these infections can be prevented. A proposed national initiative, Ending the HIV Epidemic: A Plan for America, incorporates three strategies (diagnose, treat, and prevent HIV infection) and seeks to leverage testing, treatment, and preexposure prophylaxis (PrEP) to reduce new HIV infections in the United States by at least $90 \%$ by 2030. Targets to reach this goal include that at least $95 \%$ of persons with HIV receive a diagnosis, $95 \%$ of persons with diagnosed HIV infection have a suppressed viral load, and $50 \%$ of those at increased risk for acquiring HIV are prescribed PrEP. Using surveillance, pharmacy, and other data, CDC determined the current status of these three initiative strategies.

Methods: CDC analyzed HIV surveillance data to estimate annual number of new HIV infections (2013-2017); estimate the percentage of infections that were diagnosed (2017); and determine the percentage of persons with diagnosed HIV infection with viral load suppression (2017). CDC analyzed surveillance, pharmacy, and other data to estimate PrEP coverage, reported as a percentage and calculated as the number of persons who were prescribed PrEP divided by the estimated number of persons with indications for PrEP.

Results: The number of new HIV infections remained stable from $2013(38,500)$ to $2017(37,500)$ ( $\mathrm{p}=0.448)$. In 2017, an estimated 85.8\% of infections were diagnosed. Among 854,206 persons with diagnosed HIV infection in 42 jurisdictions with complete reporting of laboratory data, $62.7 \%$ had a suppressed viral load. Among an estimated 1.2 million persons with indications for use of PrEP, 18.1\% had been prescribed PrEP in 2018.

Conclusion: Accelerated efforts to diagnose, treat, and prevent HIV infection are needed to achieve the U.S. goal of at least $90 \%$ reduction in the number of new HIV infections by 2030 .

\section{Introduction}

Since 2013, progress in reducing the number of new human immunodeficiency virus (HIV) infections has stalled at approximately 38,000 new infections occurring each year (1). Infections are preventable. Persons who are aware that they have HIV infection and maintain a suppressed viral load ( $<200$ copies of HIV RNA per $\mathrm{mL}$ ) have effectively no risk of sexually transmitting the virus to HIV-negative partners (2). Nevertheless, 38\% of new HIV infections are transmitted from persons with HIV infection who are unaware of their infection. Further, $43 \%$ of new HIV infections are transmitted from persons who have received a diagnosis but are not receiving HIV medical care, and $20 \%$ of new HIV infections are transmitted from persons receiving medical care for HIV, but who are not virally suppressed (3). Preexposure prophylaxis (PrEP), a daily oral pill that includes two HIV antiretroviral medications (tenofovir and emtricitabine), has been found to be highly effective in preventing acquisition of HIV infection (4). PrEP coverage has increased in recent years; however, coverage among persons at risk for exposure remains low (5). In February 2019, a new national initiative, Ending the HIV Epidemic: A Plan for America, was proposed. The plan calls for intensified efforts to diagnose, treat, and prevent HIV infections in the United States, with an overall goal of reducing new infections by at least $90 \%$ by 2030 (G). Use of $\mathrm{PrEP}$ is a major component of the prevention strategy and is indicated for men and women with sexual or injection drug use behaviors that increase their risk for acquiring HIV (7). To focus national and local prevention efforts on eliminating HIV, CDC analyzed surveillance, pharmacy, and other data to determine the status of these strategies (diagnose, treat, and prevent HIV infections) at the national and state levels. 


\section{Summary}

What is already known about this topic?

The approximately 38,000 new human immunodeficiency virus (HIV) infections that occur annually in the United States are preventable through testing, treatment, and preexposure prophylaxis (PrEP). A proposed initiative seeks to reduce new infections by at least $90 \%$ by 2030 . The targets for the initiative are at least $95 \%$ for testing and treatment and 50\% for PrEP.

What is added by this report?

In $2017,85.8 \%$ of persons with HIV infection had received a diagnosis, and $62.7 \%$ of persons with diagnosed HIV infection had a suppressed viral load. In 2018, PrEP had been prescribed to $18.1 \%$ of persons with indications.

What are the implications for public health practice?

Accelerated efforts to diagnose, treat, and prevent HIV infection are urgently needed.

\section{Methods}

CDC analyzed data reported to the National HIV Surveillance System (NHSS) from the beginning of the epidemic in the early 1980s through June 2019 from 50 states and the District of Columbia (DC) for persons aged $\geq 13$ years with diagnosed HIV infection. A CD4-depletion model* $^{*}(8)$ was applied to NHSS data to estimate 1 ) the annual number of new HIV infections (2013-2017); 2) the total number of persons living with HIV (diagnosed and undiagnosed infection, or prevalence) at year-end 2017; and 3) the percentage of persons with HIV infection who had received a diagnosis.

NHSS data reported from 41 states and DC that had complete laboratory reporting of viral load test results were used to determine two viral suppression measures: viral suppression among persons with diagnosed HIV infection in the jurisdiction at year-end 2017 and viral suppression within 6 months of diagnosis among persons with HIV infection diagnosed during 2017. These 42 jurisdictions represent $89 \%$ of persons with diagnosed HIV infection in the United States.

CDC analyzed national pharmacy data from the IQVIA Real World Data-Longitudinal Prescriptions database to estimate the number of persons aged $\geq 16$ years who were prescribed PrEP in 2017 and 2018. The annual number of PrEP prescriptions for persons aged $\geq 16$ years was determined using an algorithm that included persons who had at least one tenofovir disoproxil fumarate and emtricitabine (TDF/FTC)

\footnotetext{
${ }^{*}$ The first CD4 test result after HIV diagnosis and a CD4-depletion model indicating disease progression or duration after infection were used to estimate the number of new HIV infections and total prevalence (persons living with diagnosed or undiagnosed infection) among adults and adolescents in the United States.
}

prescription for $>28$ days and for whom TDF/FTC was not prescribed for HIV treatment, hepatitis B treatment, or HIV postexposure prophylaxis $(5,9)$. NHSS, National Health and Nutrition Examination Survey, and U.S. Census data were used to estimate the number of persons aged $\geq 16$ years with indications for PrEP (10). PrEP coverage, reported as a percentage, was calculated as the number of persons who were prescribed PrEP divided by the estimated number of persons who had indications for PrEP. To estimate PrEP coverage by race/ethnicity, the proportion among those with recorded race/ ethnicity data was applied to those with missing race/ethnicity data. Analyses were conducted using SAS statistical software (version.9.4; SAS Institute).

\section{Results}

The annual number of new HIV infections remained stable from $2013(38,500)$ to $2017(37,500)$ ( $\mathrm{p}=0.448)$. Among the estimated 1.2 million persons living with HIV infection in $2017,85.8 \%$ (95\% confidence interval [CI] = 84.3-87.5) had received a laboratory-confirmed diagnosis of HIV infection. The lowest percentages of diagnosed HIV infections were among persons aged 13-24 years $(54.6 \%$, 95\% CI $=52.7-56.7)$, American Indians/Alaska Natives (79.5\%, 95\% CI $=58.7-100.0)$, and heterosexual males (82.0\%, 95\% CI = 76.5-88.3), compared with other age, $\mathrm{racial} / \mathrm{ethnic}$, or transmission risk groups. (Table 1). The percentage of diagnosed infections ranged from $79.7 \%$ in Nevada to $94.4 \%$ in New Jersey (Table 2).

In $2017,62.7 \%$ of 854,206 persons with diagnosed HIV infections in 42 jurisdictions had a suppressed viral load (Table 1). The lowest percentages of persons with viral suppression were those aged 13-24 years (56.9\%), blacks/African Americans (blacks) (57.4\%), and males who inject drugs (52.0\%), compared with other age, racial/ethnic, and transmission risk groups. The percentage of persons with a suppressed viral load ranged from $47.0 \%$ in South Dakota to $79.6 \%$ in Iowa (Table 2). The percentage of persons with a suppressed viral load within 6 months of diagnosis of HIV infection was 61.5 overall and $<59 \%$ in 12 jurisdictions (Figure).

An estimated 1.2 million persons had indications for PrEP; $12.6 \%$ were prescribed PrEP in 2017 and $18.1 \%$ in 2018. In 2018, PrEP coverage was three times as high among males $(20.8 \%)$ as among females $(6.6 \%)$ (Table 1$)$. Compared with other age groups, the lowest PrEP coverage rate was among persons aged 16-24 years (11.4\%). Adjusting for missing race/ethnicity, PrEP coverage was 5.9\% for blacks, $10.9 \%$ for Hispanics/Latinos, and $42.1 \%$ for whites. PrEP coverage ranged from $5.0 \%$ in Wyoming to $41.1 \%$ in New York (Table 2). 
TABLE 1. Percentage of diagnosed human immunodeficiency virus (HIV) infections, viral suppression among persons with diagnosed HIV infection, and prescription of preexposure prophylaxis (PrEP) for persons with indications, by demographic and transmission categories United States, 2017 and 2018

\begin{tabular}{|c|c|c|c|}
\hline \multirow[b]{2}{*}{ Characteristic } & \multicolumn{2}{|c|}{2017} & \multirow{2}{*}{ 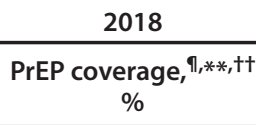 } \\
\hline & $\begin{array}{c}\text { Diagnosed HIV infection,* } \\
\%(95 \% \mathrm{Cl})\end{array}$ & $\begin{array}{c}\text { Viral suppression, }{ }^{\dagger, \S} \\
\%\end{array}$ & \\
\hline \multicolumn{4}{|l|}{ Sex } \\
\hline Male & $84.9(83.1-86.8)$ & 63.3 & 20.8 \\
\hline Female & $89.1(86.1-92.3)$ & 60.8 & 6.6 \\
\hline \multicolumn{4}{|l|}{ Age group (yrs) } \\
\hline $13-24$ & $54.6(52.7-56.7)$ & 56.9 & 11.4 \\
\hline $25-34$ & $70.4(69.4-71.4)$ & 58.1 & 21.5 \\
\hline $35-44$ & $84.5(83.6-85.4)$ & 60.2 & 21.9 \\
\hline $45-54$ & $92.2(91.5-92.9)$ & 64.6 & 17.4 \\
\hline$\geq 55$ & $94.7(93.9-95.5)$ & 65.5 & 14.4 \\
\hline \multicolumn{4}{|l|}{ Race/Ethnicity } \\
\hline American Indian/Alaska Native & $79.5(58.7-100.0)$ & 62.0 & —§ \\
\hline Asian & 83.7 (72.6-98.9) & 68.3 & —§§ \\
\hline Black/African American & $85.5(83.1-88.0)$ & 57.4 & 5.9 \\
\hline Hispanic/Latino & $83.0(79.8-86.5)$ & 62.3 & 10.9 \\
\hline Native Hawaiian/Other Pacific Islander & - $^{*}$ & 65.0 & —§§ \\
\hline White & 88.6 (85.8-91.5) & 69.3 & 42.1 \\
\hline Multiple races & $86.7(80.5-94.0)$ & 69.9 & —§§ \\
\hline \multicolumn{4}{|l|}{ Transmission category } \\
\hline Male-to-male sexual contact & $83.7(81.7-85.8)$ & 65.7 & —§§ \\
\hline Injection drug use & $93.8(89.1-99.0)$ & —าก & —§§ \\
\hline Male & $93.3(87.0-100.0)$ & 52.0 & —§§ \\
\hline Female & $94.4(87.9-100.0)$ & 58.4 & —§ \\
\hline Male-to-male sexual contact and injection drug use & $92.0(85.9-99.0)$ & 63.1 & —§ \\
\hline Heterosexual contact & $85.9(83.0-89.0)$ & —าก & —§ \\
\hline Male & $82.0(76.5-88.3)$ & 57.6 & -§§ \\
\hline Female & $87.7(84.4-91.2)$ & 61.8 & —§ \\
\hline Total & $85.8 * * *(84.3-87.5)$ & $62.7^{* * *}$ & 18.1 \\
\hline
\end{tabular}

Abbreviation: $\mathrm{Cl}$ = confidence interval.

* Percentage of diagnosed infections calculated as the number of persons who received a diagnosis of HIV infection divided by the number of persons living with HIV (diagnosed and undiagnosed; $n=1,153,400$ ). Dash in this column indicates estimate not available for some populations because of high relative standard errors.

+ Percentage viral suppression calculated as the number of persons with a viral load test result of $<200$ copies of HIV RNA per mL at last test divided by the number of persons living with diagnosed HIV infection $(n=854,206)$.

$\S$ Includes data for 42 jurisdictions (41 states and District of Columbia) with complete laboratory reporting. These jurisdictions include Alabama, Alaska, California, Colorado, Connecticut, Delaware, District of Columbia, Florida, Georgia, Hawaii, Illinois, Indiana, lowa, Louisiana, Maine, Maryland, Massachusetts, Michigan, Minnesota, Mississippi, Missouri, Montana, Nebraska, New Hampshire, New Mexico, New York, North Carolina, North Dakota, Ohio, Oklahoma, Oregon, Rhode Island, South Carolina, South Dakota, Tennessee, Texas, Utah, Virginia, Washington, West Virginia, Wisconsin, and Wyoming.

I PrEP coverage, calculated as the number of persons who were prescribed PrEP ( $\mathrm{n}=219,691$ in 2018) divided by estimated number of persons with indications for $\operatorname{PrEP}(\mathrm{n}=1,211,777$ in 2017).

** Total includes 1,605 persons prescribed PrEP with unknown jurisdiction and 143,168 persons prescribed PrEP with unknown/unavailable race/ethnicity. PrEP coverage for race/ethnicity was adjusted applying the distribution of records with known race/ethnicity to records with missing race/ethnicity.

${ }^{+\dagger}$ Age group for PrEP coverage is $16-24$ years.

$\S \S$ Dashes indicate data not available. IQVIA data source has incomplete race/ethnicity data and does not collect data on transmission risk category.

กศ Percentage viral suppression is presented for each sex within transmission category.

*** Total includes persons with HIV infection attributed to hemophilia, blood transfusion, perinatal exposure, or whose risk factor was not reported or not identified.

\section{Discussion}

The annual number of new HIV infections has remained relatively stable since 2013 . In 2017 , the percentage of persons with HIV infection whose infection was diagnosed was $86 \%$, a significant increase from 83\% in 2010 (1). Overall, in $2017,63 \%$ of persons with diagnosed HIV infection had a suppressed viral load, and in 2018, PrEP coverage was low at $18 \%$. These findings confirm substantial gaps in diagnosing, treating, and preventing HIV infection and underscore the need for expanded efforts. The targets for the proposed initiative are at least $95 \%$ of persons with HIV infection having received a diagnosis, $95 \%$ of persons with diagnosed HIV infection having a suppressed viral load, and $50 \%$ of persons with indications for PrEP having been prescribed PrEP (11). New infections will occur unless substantial improvements are made in implementing these three strategies.

In this analysis, the lowest percentages of diagnosed HIV infection were among young persons (aged 13-34 years), American Indians/Alaska Natives, and heterosexual males. The low percentage of diagnosed HIV infection in these three populations might be explained by 1) lower testing rates among youths (12), 2) HIV-related stigma and lack of 
TABLE 2. Percentage of diagnosed human immunodeficiency virus (HIV) infections, viral suppression among persons with diagnosed HIV infection, and prescription of preexposure prophylaxis (PrEP) for persons with indications, by jurisdiction - United States, 2017 and 2018

\begin{tabular}{|c|c|c|c|}
\hline \multirow[b]{2}{*}{ Jurisdiction } & \multicolumn{2}{|c|}{2017} & \multirow{2}{*}{$\frac{2018}{\begin{array}{c}\text { PrEP coverage, } \\
\%\end{array}}$} \\
\hline & $\begin{array}{c}\text { Diagnosed HIV infection,* } \\
\%(95 \% \mathrm{Cl})\end{array}$ & $\begin{array}{c}\text { Viral suppression, }{ }^{t, \S} \\
\%\end{array}$ & \\
\hline Alabama & $83.9(72.2-100.0)$ & 57.3 & 13.2 \\
\hline Alaska & - $^{*}$ & 78.7 & 8.3 \\
\hline Arizona & 84.7 (74.1-98.8) & —§ & 13.1 \\
\hline Arkansas & $82.2(66.3-100.0)$ & —§ & 12.5 \\
\hline California & $85.9(81.6-90.5)$ & 66.6 & 21.9 \\
\hline Colorado & $85.8(74.5-100.0)$ & 58.6 & 13.3 \\
\hline Connecticut & $88.6(75.1-100.0)$ & 66.8 & 21.3 \\
\hline Delaware & $85.5(64.9-100.0)$ & 67.7 & 8.7 \\
\hline District of Columbia & $88.6(76.9-100.0)$ & 56.0 & 36.5 \\
\hline Florida & $87.0(82.3-92.3)$ & 63.0 & 11.1 \\
\hline Georgia & $82.0(76.0-89.1)$ & 58.3 & 15.2 \\
\hline Hawaii & $85.5(63.1-100.0)$ & 68.2 & 12.2 \\
\hline Idaho & $96.6(65.3-100.0)^{\dagger+}$ & —§ & 10.0 \\
\hline Illinois & 85.6 (77.9-94.9) & 53.8 & 26.8 \\
\hline Indiana & $83.8(71.5-100.0)$ & 61.3 & 10.1 \\
\hline lowa & $82.3(61.6-100.0)$ & 79.6 & 28.1 \\
\hline Kansas & $84.0(63.3-100.0)$ & —§ & 13.9 \\
\hline Kentucky & $82.7(68.3-100.0)$ & $-\S$ & 9.2 \\
\hline Louisiana & $81.2(71.7-93.7)$ & 64.7 & 22.8 \\
\hline Maine & $85.9(59.8-100.0)$ & 78.3 & 11.9 \\
\hline Maryland & 86.1 (78.1-95.9) & 58.2 & 14.3 \\
\hline Massachusetts & $89.5(79.6-100.0)$ & 70.9 & 33.4 \\
\hline Michigan & $83.1(72.2-97.9)$ & 72.2 & 12.2 \\
\hline Minnesota & $84.9(71.8-100.0)$ & 69.1 & 15.1 \\
\hline Mississippi & $87.9(73.8-100.0)$ & 49.2 & 12.9 \\
\hline Missouri & $85.2(73.4-100.0)$ & 66.2 & 14.2 \\
\hline Montana & - $^{*}$ & 78.5 & 6.6 \\
\hline
\end{tabular}

See table footnotes on next page.

access to HIV-related services among American Indians/Alaska Natives (13), and 3) low patient and provider perceived risk for HIV acquisition among heterosexuals (14). The percentage of diagnosed HIV infections also varied geographically, possibly reflecting differences in access to and implementation of HIV testing and highlighting the need for developing tailored testing strategies (15). CDC recommends routine screening of all persons aged 13-64 years at least once in their lifetime (16), yet recent findings indicate that only $40 \%$ of persons aged $\geq 18$ years in the United States have ever been tested for HIV (15). HIV testing guidelines also recommend at least annual testing for persons at high risk for acquiring HIV. Accelerating implementation of HIV testing strategies such as integrated and routinized HIV screening in health care settings, scaling up partner notification, social/sexual network screening, and mass distribution of HIV self-test kits (15) might facilitate early diagnosis.

The lowest percentages of viral suppression were found among young persons, blacks, and heterosexual males. Adherence to medication is critical to viral suppression. Factors associated with lower adherence or viral suppression include young age (17) and, for blacks, include health care coverage, homelessness, and incarceration (18). Expanded efforts must address these and other social and economic barriers to care.
Developing or scaling up the implementation of evidencebased interventions is also important for improving adherence and viral suppression among youths and blacks. For example, one successful approach to improving viral suppression among blacks with HIV infection is an integrated care model that includes collaboration between community pharmacists and HIV medical care providers to develop individualized care plans that address HIV treatment challenges (19).

Since 2012, prompt treatment with antiretroviral therapy after diagnosis of HIV infection, regardless of stage of disease, has been recommended (20). Yet only $61.5 \%$ of persons with HIV infection diagnosed in 2017 had a suppressed viral load within 6 months of diagnosis. Low viral suppression rates within 6 months of HIV diagnosis (59\%) occurred mainly in Southern states, which are already disproportionately affected by HIV (1). One study in patients with high rates of mental health illness, drug use, and housing instability illustrated success in reaching viral suppression within 1 year using multidisciplinary care and other support (21). To rapidly improve viral suppression for all populations, additional research is needed to identify interventions that will achieve viral suppression within 6 months of diagnosis, especially among populations facing severe health and socioeconomic challenges, including homelessness (22). 
TABLE 2. (Continued) Percentage of diagnosed human immunodeficiency virus (HIV) infections, viral suppression among persons with diagnosed HIV infection, and prescription of preexposure prophylaxis (PrEP) for persons with indications, by jurisdiction — United States, 2017 and 2018

\begin{tabular}{|c|c|c|c|}
\hline \multirow[b]{2}{*}{ Jurisdiction } & \multicolumn{2}{|c|}{2017} & \multirow{2}{*}{$\begin{array}{c}2018 \\
\begin{array}{c}\text { PrEP coverage, } \\
\%\end{array}\end{array}$} \\
\hline & $\begin{array}{c}\text { Diagnosed HIV infection, } * \\
\%(95 \% \mathrm{Cl})\end{array}$ & $\begin{array}{c}\text { Viral suppression, }{ }^{\dagger, \S} \\
\%\end{array}$ & \\
\hline Nebraska & $82.7(59.8-100.0)$ & 64.2 & 18.8 \\
\hline Nevada & 79.7 (67.4-97.4) & -§ & 13.5 \\
\hline New Hampshire & $85.5(57.0-100.0)^{t+}$ & 70.3 & 21.0 \\
\hline New Jersey & $94.4(85.6-100.0)$ & -§ & 16.8 \\
\hline New Mexico & $81.2(61.7-100.0)$ & 68.5 & 12.0 \\
\hline New York & $88.3(84.0-93.0)$ & 63.2 & 41.1 \\
\hline North Carolina & $87.3(79.0-97.5)$ & 63.2 & 11.1 \\
\hline North Dakota & - ${ }^{*}$ & 77.7 & 14.8 \\
\hline Ohio & $83.9(74.8-95.5)$ & 54.7 & 11.6 \\
\hline Oklahoma & $82.9(66.8-100.0)$ & 59.0 & 7.6 \\
\hline Oregon & $85.9(71.4-100.0)$ & 63.7 & 13.6 \\
\hline Pennsylvania & $92.7(84.6-100.0)$ & — & 22.9 \\
\hline Rhode Island & $84.5(62.2-100.0)$ & 76.6 & 18.9 \\
\hline South Carolina & $84.1(73.9-97.5)$ & 66.3 & 11.7 \\
\hline South Dakota & - ${ }^{*}$ & 47.0 & 11.3 \\
\hline Tennessee & $84.9(74.2-99.2)$ & 57.6 & 11.4 \\
\hline Texas & $81.1(76.3-86.6)$ & 61.3 & 14.3 \\
\hline Utah & $81.9(61.1-100.0)$ & 62.5 & 21.9 \\
\hline Vermont & $93.0(59.0-100.0)^{+\dagger}$ & —§ & 17.7 \\
\hline Virginia & $86.9(77.5-98.8)$ & 55.2 & 9.5 \\
\hline Washington & $88.3(76.9-100.0)$ & 78.6 & 25.0 \\
\hline West Virginia & $86.9(61.4-100.0)$ & 58.9 & 9.7 \\
\hline Wisconsin & $83.7(68.3-100.0)$ & 74.5 & 14.3 \\
\hline Wyoming & -* & 76.8 & 5.0 \\
\hline Total & $85.8(84.3-87.5)$ & 62.7 & 18.1 \\
\hline
\end{tabular}

Abbreviation: $\mathrm{Cl}=$ confidence interval.

* Percentage of diagnosed infections calculated as the number of persons who received a diagnosis of HIV infection divided by the number of persons living with

HIV (diagnosed and undiagnosed). Dashes in this column indicate estimates not available for some jurisdictions because of high relative standard errors.

† Percentage viral suppression calculated as the number of persons with a viral load test result of $<200$ copies of HIV RNA per mL at last test divided by the number of persons living with diagnosed HIV infection.

$\S$ Includes data for 42 jurisdictions (41 states and District of Columbia) with complete laboratory reporting. These jurisdictions include Alabama, Alaska, California, Colorado, Connecticut, Delaware, District of Columbia, Florida, Georgia, Hawaii, Illinois, Indiana, lowa, Louisiana, Maine, Maryland, Massachusetts, Michigan, Minnesota, Mississippi, Missouri, Montana, Nebraska, New Hampshire, New Mexico, New York, North Carolina, North Dakota, Ohio, Oklahoma, Oregon, Rhode Island, South Carolina, South Dakota, Tennessee, Texas, Utah, Virginia, Washington, West Virginia, Wisconsin, and Wyoming. Data were incomplete or not reported for nine jurisdictions, as indicated by dashes.

9 PrEP coverage calculated as the number of persons who were prescribed PrEP (in 2018) divided by estimated number of persons with indications for PrEP (in 2017). ** Total includes 1,605 PrEP users with unknown jurisdiction.

${ }^{+\dagger}$ Estimate does not meet the standard of reliability; use with caution.

In 2019, the United States Preventive Services Task Force issued a Grade A recommendation ${ }^{\dagger}$ that clinicians offer PrEP to persons at substantial risk for HIV acquisition (4). Overall, PrEP coverage was 9\% in 2016 (5) and improved to $18 \%$ in 2018. Similar to earlier findings, PrEP coverage in this analysis was especially low in young persons (aged 16-24 years) compared with that in other age groups, and racial/ethnic and geographic disparities in PrEP prescription exist (5). In 2018, approximately $43 \%$ of HIV diagnoses were among blacks, and 26\% were among Hispanics/Latinos (23). However, PrEP coverage among whites was seven times as high as that among blacks and four times as high as that among Hispanics/Latinos, suggesting that PrEP delivery to persons

\footnotetext{
Grade A recommendation is a recommendation with high certainty that the net benefit of the intervention is substantial. https://www. uspreventiveservicestaskforce.org/Page/Name/grade-definitions.
}

in racial/ethnic minority populations has not been equitable. Improving PrEP coverage will require targeted improvements in PrEP awareness, prescribing practices, and use in underreached demographic groups, especially among young persons, blacks, and Hispanics/Latinos at risk for acquiring HIV. CDC has developed a campaign, Prescribe HIV Prevention, which is designed to help clinicians provide PrEP to prevent acquisition of HIV (24).

The findings in this report are subject to at least three limitations. First, estimation of the number of new infections and percentage of undiagnosed infections relies on the assumption that persons received no treatment before their first CD 4 test. The CD4 counts of persons with evidence of previous antiretroviral therapy use or viral suppression are excluded from the analysis, minimizing the impact of prior treatment on the HIV depletion model. Second, viral suppression measures in 
FIGURE. Viral suppression ${ }^{*}, t, \S$ within 6 months of diagnosis of human immunodeficiency virus (HIV) infection among persons aged $\geq 13$ years - United States, " 2017

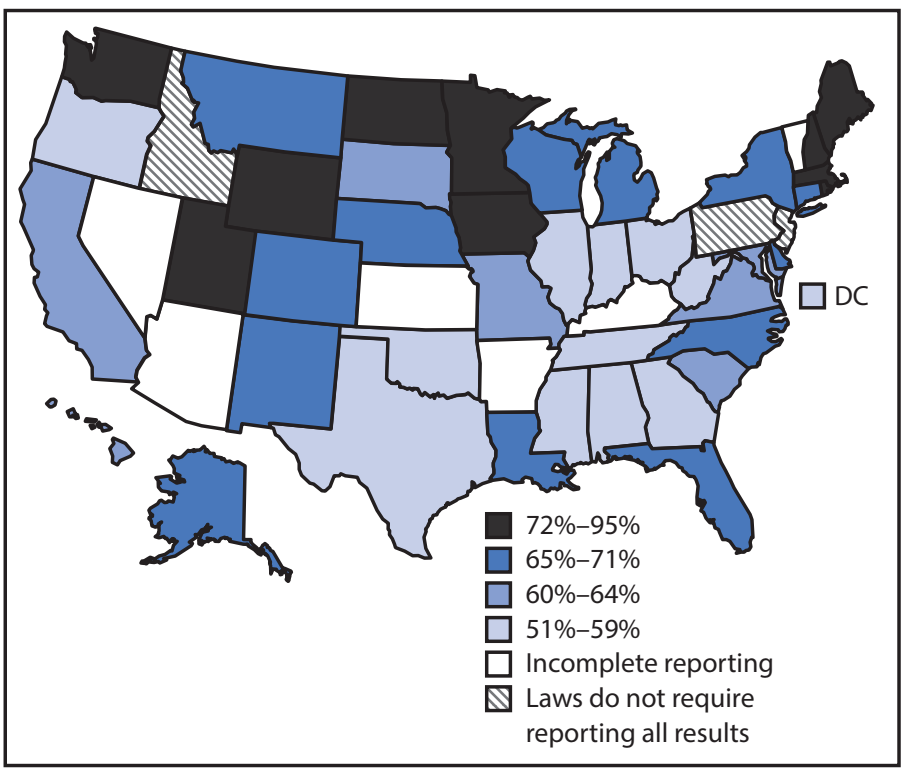

Abbreviation: $\mathrm{DC}=$ District of Columbia.

* Percentage viral suppression within 6 months of HIV diagnosis, calculated as the number of persons with a viral load test result of $<200$ copies of HIV RNA per $\mathrm{mL}$ at last test divided by the number of persons with HIV diagnosed in 2017. Residence was based on residence at the time of diagnosis of HIV infection.

${ }^{\dagger}$ Total $=61.5 \%$.

$\S$ Data classified using quartiles.

" Analysis based on data reported from 41 states and DC; data for nine states were incomplete or not reported.

this analysis were based on data from 42 jurisdictions and are therefore not necessarily representative of data on all persons living with diagnosed HIV infection in the United States. Finally, although IQVIA recorded $92 \%$ of all prescriptions from retail pharmacies in the United States, prescriptions from closed health care systems (e.g., managed care organizations or military health plans) were not included. Therefore, these are minimum estimates of PrEP coverage. Different data sources were used in the numerator and denominator to calculate PrEP coverage. Although the result is expressed as a percentage, it is unknown whether all persons prescribed $\mathrm{PrEP}$ (numerator) are also contained in the denominator of the estimate of the number of persons with indications for PrEP. In addition, only $35 \%$ of persons with PrEP prescriptions identified in the IQVIA data had race/ethnicity information available. In calculating PrEP coverage, the racial/ethnic distribution of known records was applied to those for which data on race/ ethnicity were missing, which might not be valid. The extent to which the missing race/ethnicity is the same as that for those with reported race/ethnicity is unknown. Improvements in the completeness of race/ethnicity data in prescription databases are needed to fully describe disparities in PrEP coverage.
Accelerated efforts to diagnose, treat, and provide PrEP while addressing disparities, are urgently needed to reach the targets for the Ending the HIV Epidemic: A Plan for America initiative. These accelerated efforts, along with other prevention strategies such as quickly responding to increases in diagnoses of HIV infections, will be needed to meet the ambitious U.S. goal of at least a $90 \%$ reduction in the number of new HIV infections by 2030 .

Corresponding author: Norma S. Harris, nharris@cdc.gov, 404-718-8559.

${ }^{1}$ Division of HIV/AIDS Prevention, National Center for HIV, Viral Hepatitis, STD, and TB Prevention, CDC; ${ }^{2}$ National Center for HIV, Viral Hepatitis, STD, and TB Prevention, CDC.

All authors have completed and submitted the International Committee of Medical Journal Editors form for disclosure of potential conflicts of interest. No potential conflicts of interest were disclosed.

\section{References}

1. CDC. Estimated HIV incidence and prevalence in the United States, 2010-2016. HIV surveillance supplemental report 2019. Vol 24, no. 1. Atlanta, GA: US Department of Health and Human Services, CDC; 2019. https://www.cdc.gov/hiv/pdf/library/reports/surveillance/cdc-hivsurveillance-supplemental-report-vol-24-1.pdf

2. CDC. Evidence of HIV treatment and viral suppression in preventing the sexual transmission of HIV. Atlanta, GA: US Department of Health and Human Services, CDC; 2018. https://www.cdc.gov/hiv/pdf/risk/ art/cdc-hiv-art-viral-suppression.pdf

3. Li Z, Purcell DW, Sansom SL, Hayes D, Hall HI. Vital signs: HIV transmission along the continuum of care-United States, 2016. MMWR Morb Mortal Wkly Rep 2019;68:267-72. https://doi. org/10.15585/mmwr.mm6811e1

4. Owens DK, Davidson KW, Krist AH, et al.; US Preventive Services Task Force. Preexposure prophylaxis for the prevention of HIV infection: US Preventive Services Task Force recommendation statement. JAMA 2019;321:2203-13. https://doi.org/10.1001/jama.2019.6390

5. Huang YA, Zhu W, Smith DK, Harris N, Hoover KW. HIV preexposure prophylaxis, by race and ethnicity-United States, 2014-2016. MMWR Morb Mortal Wkly Rep 2018;67:1147-50. https://doi.org/10.15585/ mmwr.mm6741a3

6. Fauci AS, Redfield RR, Sigounas G, Weahkee MD, Giroir BP. Ending the HIV epidemic: a plan for the United States. JAMA 2019;321:844-5. https://doi.org/10.1001/jama.2019.1343

7. CDC. Preexposure prophylaxis for the prevention of HIV infection in the United States - 2017 update. Atlanta, GA: US Department of Health and Human Services, CDC; 2018. https://www.cdc.gov/hiv/pdf/risk/ $\mathrm{prep} / \mathrm{cdc}$-hiv-prep-guidelines-2017.pdf

8. Song R, Hall HI, Green TA, Szwarcwald CL, Pantazis N. Using CD4 data to estimate HIV incidence, prevalence, and percent of undiagnosed infections in the United States. J Acquir Immune Defic Syndr 2017;74:3-9. https://doi.org/10.1097/QAI.0000000000001151

9. Furukawa NW, Smith DK, Gonzalez CJ, et al. Evaluation of algorithms used for PrEP surveillance using a reference population from New York City - July 2016-June 2018. Public Health Rep. In press 2019.

10. Smith DK, Van Handel M, Grey J. Estimates of adults with indications for HIV pre-exposure prophylaxis by jurisdiction, transmission risk group, and race/ethnicity, United States, 2015. Ann Epidemiol 2018;28:850-857.e9. https://doi.org/10.1016/j.annepidem.2018.05.003

11. Stein S. Trump wants $90 \%$ drop in new HIV infections, near-universal care. Bloomberg Law Health Law and Business News. October 30, 2019. https://news.bloomberglaw.com/health-law-and-business/ trump-wants-90-drop-in-new-hiv-infections-near-universal-care 
12. Kann L, McManus T, Harris WA, et al. Youth risk behavior surveillanceUnited States, 2017. MMWR Surveill Summ 2018;67(No. SS-8). https://doi.org/10.15585/mmwr.ss6708a1

13. Negin J, Aspin C, Gadsden T, Reading C. HIV among indigenous peoples: a review of the literature on HIV-related behaviour since the beginning of the epidemic. AIDS Behav 2015;19:1720-34.

14. Pringle K, Merchant RC, Clark MA. Is self-perceived HIV risk congruent with reported HIV risk among traditionally lower HIV risk and prevalence adult emergency department patients? Implications for HIV testing. AIDS Patient Care STDS 2013;27:573-84. https://doi. org/10.1089/apc.2013.0013

15. Pitasi MA, Delaney KP, Brooks JT, DiNenno EA, Johnson SD, Prejean J. HIV screening in 50 local jurisdictions accounting for the majority of new HIV diagnoses and seven states with disproportionate occurrence of HIV in rural areas, 2016-2017. MMWR Morb Mortal Wkly Rep 2019;68:561-7. https://doi.org/10.15585/mmwr.mm6825a2

16. Branson BM, Handsfield HH, Lampe MA, et al. Revised recommendations for HIV testing of adults, adolescents, and pregnant women in healthcare settings. MMWR Recomm Rep 2006;55(No. RR-14).

17. Zanoni BC, Mayer KH. The adolescent and young adult HIV cascade of care in the United States: exaggerated health disparities. AIDS Patient Care STDS 2014;28:128-35. https://doi.org/10.1089/apc.2013.0345

18. Beer L, Mattson CL, Bradley H, Skarbinski J; Medical Monitoring Project. Understanding cross-sectional racial, ethnic, and gender disparities in antiretroviral use and viral suppression among HIV patients in the United States. Medicine (Baltimore) 2016;95:e3171. https://doi. org/10.1097/MD.0000000000003171
19. Byrd KK, Hou JG, Bush T, et al. Adherence and viral suppression among participants of the patient-centered human immunodeficiency virus (HIV) care model project: a collaboration between community-based pharmacists and HIV clinical providers. Clin Infect Dis 2019;ciz276 April 6, 2019. https://doi.org/10.1093/cid/ciz276

20. Panel on Antiretroviral Guidelines for Adults and Adolescents. Guidelines for the use of antiretroviral agents in adults and adolescents with HIV. Washington, DC: US Department of Health and Human Services; 2019. https://aidsinfo.nih.gov/contentfiles/lvguidelines/ AdultandAdolescentGL.pdf

21. Coffey S, Bacchetti P, Sachdev D, et al. RAPID antiretroviral therapy: high virologic suppression rates with immediate antiretroviral therapy initiation in a vulnerable urban clinic population. AIDS 2019;33:825-32. https://doi.org/10.1097/QAD.0000000000002124

22. Aidala AA, Wilson MG, Shubert V, et al. Housing status, medical care, and health outcomes among people living with HIV/AIDS: a systematic review. Am J Public Health 2016;106:e1-23. https://doi.org/10.2105/ AJPH.2015.302905

23. CDC. Diagnoses of HIV infection in the United States and dependent areas, 2018. HIV surveillance report. Vol. 30. Atlanta, GA: US Department of Health and Human Services, CDC; 2019. https://www. cdc.gov/hiv/library/reports/hiv-surveillance.html

24. CDC. Let's stop HIV together: prescribe HIV prevention. Atlanta, GA: US Department of Health and Human Services, CDC; 2019. https:// www.cdc.gov/stophivtogether/campaigns/prescribe-hiv-prevention/ index.html 